\title{
Political Marketing: Measurement Parameters of the Concept of Social Value in Possible Presidential Pre-candidates, Elections 2021, Chimborazo, Ecuador
}

\section{Marketing Político: Parámetros de Medición del Concepto del Valor Social en los Posibles Pre-candidatos Presidenciales, Elecciones 2021, Chimborazo, Ecuador}

Science, Technology,

Entrepreneurship and

Innovation (SECTEI 2020)

Corresponding Author:

L. Vallejo

luz.vallejo@espoch.edu.ec

Published: 26 August 2021

Production and Hosting by

Knowledge $E$

(c) L. Vallejo et al. This article is distributed under the terms of the Creative Commons Attribution License, which permits unrestricted use and redistribution provided that the original author and source are credited.
S OPEN ACCESS

\section{Vallejo ${ }^{1}$, M. Torreso², C. Buenaño ${ }^{1}$, and C. Buenaño ${ }^{1}$}

${ }^{1}$ Facultad de Administración de Empresas, Escuela Superior Politécnica de Chimborazo, Riobamba, Ecuador

${ }^{2}$ Universidad Estatal Amazónica, Puyo, Ecuador

\section{Abstract}

This research sought to determine what parameters of social value should be met by potential presidential candidates through an analysis of political marketing. Qualitative and quantitative approaches were used, at a descriptive, observational and prospective level, with a non-experimental cross-sectional design. Inductive, deductive, analytical, synthetic and semantic methods were used in documentary review and preparation of the conclusions. The objective was to determine the parameters of social value used by voters to evaluate the acceptance / rejection of six possible candidates. The investigation was limited to the province of Chimborazo, Sierra region, after the events of October 2019. The seven social value parameters established by policy experts were: credibility, political background, honesty, professional training, leadership, charisma and tolerance. The results showed a preference in the Chimborazo province for the left-wing political parties and candidates. We conclude that the chimboracenses voters comparatively determined their perception of acceptance / rejection of candidates visible after the national strike in October 2019 using seven predetermined parameters.

Keywords: concepts of value, pre-candidates, political marketing, candidate, political parties.

\section{Resumen}

La investigación buscó determinar que parámetros de medición del concepto valor social debería cumplir los posibles precandidatos presidenciales mediante un análisis de Marketing Político, la investigación de enfoque cualitativo y cuantitativo, de nivel descriptivo, observacional y prospectivo, de diseño transversal no experimental, se aplicó los métodos: inductivo, deductivo, analítico, sintético y semántico en la revisión documental y elaboración de las conclusiones. El objetivo de la investigación fue determinar los parámetros de medición del concepto valor social para evaluar la aceptación/rechazo de los electores en seis posibles precandidatos, la investigación muestra limitación en la provincia de Chimborazo, región sierra, luego de los hechos sucedidos el pasado octubre-2019. Los parámetros identificados en el concepto valor social fueron establecidos por expertos en política definiéndose siete: 
credibilidad, antecedentes políticos, honradez, formación profesional, liderazgo, carisma y tolerancia. Los resultados avizoran un buen posicionamiento en la provincia de Chimborazo hacia los candidatos y partidos políticos de izquierda. Se concluye que, los electores chimboracenses en forma comparativa determinaron su percepción de aceptación/rechazo en 7 parámetros descritos en los precandidatos que se visibilizaron después del Paro Nacional de octubre 2019.

Palabras Clave: conceptos de valor, pre-candidatos, marketing político, candidato, partidos políticos.

\section{Introducción}

El marketing político permite analizar las nuevas tendencias electorales para comprender el comportamiento de los electores ante los posibles candidatos presidenciales, según los autores [1] manifiestan que:

se puede inferir con el marketing político, que es una disciplina orientada a la creación y desarrollo de conceptos políticos relacionados con partidos o candidatos específicos, para que los partidos/candidatos logren satisfacer las expectativas de determinados grupos de electores, con el objetivo que los electores les otorguen su voto.

Se deduce que el marketing político es una disciplina que ha surgido desde tiempos remotos en los imperios griego y romano. El término de 'Marketing Político' se introdujo a mediados del siglo XX en Estados Unidos, influenciada por la campaña del entonces candidato a la presidencia de Estados Unidos Jhon F. Kennedy (1960). Desde ese año se ha reconocido la importancia de los profesionales del marketing quienes transmiten ideas adecuadas para influenciar con un impacto en el votante.

Pues bien, el Marketing Político se mueve dentro de un mercado complejo muy diferente a los productos y servicios. Es decir, es un mercado donde las demandas son más conflictivas y complicadas, siendo el producto político un producto intangible difícil de crear y comprender, pues se valora los aspectos éticos y morales que son factores determinantes en un consumidor político, para que el votante prefiera la oferta de un político y rechace totalmente la oferta de los demás contendientes.

Por tal motivo, es importante determinar quiénes son los actores políticos para identificar su comportamiento, se define de la siguiente manera:

1. El producto político son los Candidato y Partidos Políticos.

2. Consumidor político son los electores o votantes 
Ramos et al. manifiestan que: El Marketing Político es una disciplina en constante movimiento y evolución; en este sentido, los actores identificados son los productos políticos, los consumidores políticos y la evolución de las técnicas de comunicación [2].

De la misma manera, la elocuencia personal e intuitiva se complementa en la comunicación y persuasión. de los candidatos hacia el electorado quien debe tener un conocimiento del consumidor político, sus percepciones y aspiraciones en el candidato.

El objetivo de la investigación es identificar los conceptos de valor social en los posibles pre-candidatos presidenciales para las elecciones de 2021 en Ecuador. Los objetivos específicos del estudio son: (i) Realizar un estudio de mercado al electorado para medir las percepciones del concepto valor social en los posibles candidatos presidenciales para las elecciones de 2021 en Ecuador. (ii) Realizar un análisis descriptivo e interpretativo de los resultados obtenidos en la investigación.

Es importante comprender el concepto de valor social el mismo que se puede ajustarse o reorganizarse a lo largo del tiempo a medida que las necesidades de la sociedad y de los individuos se modifican. Por lo tanto, no existe un orden estricto de cuáles son los valores sociales más importantes. Según [3] manifiesta que: Los valores sociales son un conjunto de valores reconocidos como parte del comportamiento social que se espera de los candidatos que forman parte una comunidad. Son una clasificación de los valores en general, entendiendo que son una representación de las cualidades y las virtudes que poseen y representan un candidato.

La investigación explora los conceptos en el ámbito político que permiten realizar un análisis cualitativo del mercado del electorado, fijar objetivos y estrategias electorales para el lanzamiento del candidato y así generar un posicionamiento en el mercado político con el fin de definir un programa electoral o plataforma promocional de comunicación y crear una campaña de publicidad de imagen con la aplicación de estrategias de relaciones públicas que apoyen a la candidatura.

Es así que el consumidor político identifica ciertos rasgos o características que debe cumplir su candidato político que pretenden maneja el poder del Estado, es por ello importante cuan creíble es el discurso político donde se maneja las emociones y sentimientos en el elector al identificar el arquetipo del candidato. Se necesita una labor de persuasión ante un electorado donde se conocen sus aspiraciones y motivaciones, el procedimiento es parecido en la forma de dar a conocer al público un producto, de aquí surge la denominación de marketing político que son las acciones que permiten el refuerzo de la imagen del candidato para crear posibilidades de elección mediante técnicas promocionales o publicitarias procedentes del marketing.

El marketing político en una ciencia social que impulsa la vida política de la democracia. Su objetivo es la comunicación entre candidato, partido y elector que, mediante el conocimiento del candidato, su imagen que proyecta, el discurso que maneja incide o 
no en su voto en las urnas electorales, donde los candidatos pretenden resolver problemas de naturaleza económica, social y política para captar los votos del electorado.

El marketing político técnicamente constituye la expresión específica de la política actual, al identificarse política con democracia, y democracia con urnas que son los objetivos del marketing político, al igual que el acto de compra que realiza el cliente en la actividad comercial.

El riesgo del marketing político es que, se utilice para hacer demagogia y aún peor un discurso libre de democracia que conduzca a la degradación y corrupción, convirtiendo en regímenes muy lejanos de la verdadera y deseable representación y participación del pueblo en la política.

El conocimiento del electorado permite la conquista electoral del poder y el mantenerse una vez logrado, se constituye el fin principal de la actividad política en la democracia. La investigación y análisis del mercado electoral, en la entrada de acción de todo plan y estrategia de marketing, tanto político como empresarial. Para prever el comportamiento de los electores y más aún, para poder influir en el electorado, es necesario, ante todo, conocer los mecanismos y las causas del voto, para después incidir sobre ellos y modificar los contenidos del mensaje.

Mediante estudios de mercado de tipo cualitativo se analiza: La segmentación, la tipología de las necesidades, la percepción e imagen de los candidatos en cada jurisdicción, el perfil ideal del candidato, los determinantes del acto de voto, entre otros. El estudio del electorado es preciso para conocer las aspiraciones profundas y cómo piensan los diferentes conjuntos de electores sobre los valores sociales que debe tener un candidato. Siendo importante las actitudes del candidato y el manejo de los medios de difusión que llegan a cada segmento de la población.

La pregunta es ¿qué valores sociales entran en juego al elegir al candidato? Existen modelos de comportamiento que constituyen representaciones de los procesos de elección que permiten el análisis de las variables significativas y la determinación de cuáles de ellas son realmente importantes a la hora de explicar el fenómeno de elegir un candidato y permiten orientar las acciones del marketing político para conocer el proceso de decisión del voto del elector. Se trata de determinar cuáles son los criterios evaluativos que los individuos utilizan para elegir y valorar a los pre-candidatos, situaciones y contextos de análisis forma una decisión.

Los criterios de decisión, que a menudo no son percibidos conscientemente por el propio individuo, pueden ser de carácter objetivo o de naturaleza subjetiva o simbólica. Son en todo caso, producto de la personalidad, experiencia e información almacenada, y de las diferentes influencias sociales recibidas.

El problema que se han planteado los partidos políticos es: ¿Cómo determinar cuáles son los criterios de valor que debe contener un candidato? y ¿Cuál es su importancia relativa en las decisiones del electorado? para que, a partir de ahí, ofrecer una imagen 
acorde con los mismos o ensayar diferentes procedimientos para cambiar estos criterios en él candidato, bien en número o en orden de importancia. Es así que, las respuestas del elector hacia un determinado candidato vienen determinadas por la imagen que él, tiene de éste. Consecuentemente, el análisis del proceso de decisión del voto conduce al estudio de la formación y evaluación de la imagen que los electores se han creado de cada político. Otros expertos prefieren considerar que el comportamiento político es manifestación de las actitudes políticas, que se verán reflejadas en el voto.

Desde la perspectiva de un elector, una actitud es un estado de afectividad dada alguna característica al candidato, una disposición de ánimo que se manifiesta exteriormente. Las percepciones se fundamentan en tres componentes: Cognoscitivo, afectivo y de comportamiento. El componente cognoscitivo refleja del conocimiento y creencias de un individuo acerca de un determinado candidato o partido político. El componente afectivo se refiere al gusto, preferencia y sentimientos del individuo acerca de un determinado candidato o partido. Finalmente, el componente de comportamiento podría traducirse por la intención de apoyo, afiliación o voto del elector.

Para Alonso [4] 'El electorado es un conglomerado voluble, inconstante y en continuo cambio. Es frágil como el vidrio, pero diferente a él en su transparencia, se rompe ante cualquier eventualidad, económica o social' ..... continúa [4] 'El electorado es como una mujer coqueta que se deja seducir fácilmente, porque siente placer en la propia seducción; sin embargo, esa manera fácil de convencer se torna agresiva, violenta e intolerante cuando desmitifica al líder'.

Por este motivo es importante determinar los conceptos de valor en el electorado hacia el precandidato; al determinar los parámetros adecuados, se realiza una estratificación social que es de importancia práctica, dado que muchos de los comportamientos electorales resultan ser decisiones y actitud homogéneas perfectamente explicables en función del grupo al que se pertenece. Podemos entender por clase social a cada división relativamente homogénea y permanente en la sociedad, dentro de la cual los individuos y familias pueden ser caracterizados por una valoración similar de la vida, estilo, interés y conducta.

En cada clase social, los individuos muestran comportamientos similares. Cada individuo normal conoce su entorno de clase y se sitúa a través de ella en conjunto en la sociedad. Un grupo de referencia es un conjunto de individuos que influyen en las actitudes y comportamientos de cada uno de ellos considerados individualmente. Dentro de estos grupos puede diferenciarse entre grupos primarios y secundarios. Primarios son aquellos pequeños agregados caracterizados fundamentalmente por la intimidad, de forma tal que sus miembros se comunican por contacto directo. El grupo primario más importante es la familia seguido de otros grupos como son los amigos o vecinos. Los secundarios son organizaciones sociales, como asociaciones religiosas, compañeros de trabajo, sindicatos entre otros. Los grupos de referencia determinan en 
gran medida la socialización de sus miembros, establecen normas de conducta y son puntos de referencia para la autovaloración de uno mismo.

La socialización, entendida como la inserción del individuó en la sociedad, es decir, cómo el proceso por el cual cada persona aprende un sistema de valores, normas y patrones de comportamiento vigentes en la sociedad o grupo al que pertenece, se desarrolla bajo la influencia directa y muy próxima de los grupos de referencia.

La comunicación interpersonal dentro de estos grupos modifica o fortalece las actitudes políticas de sus miembros en mayor medida que se produce a través de medios: De comunicación más amplios. También las áreas geográficas se caracterizan por crear su propia cultura. En cada zona, su población adopta diferentes modos de vida, estilo, conductas, procesos de decisión, exigencias. Su importancia se verá en los resultados de las últimas consultas electorales.

Según Alonso [4], a medida que la investigación de mercado propiciada por el marketing político se desarrolla se incorpora conceptos provenientes de las ciencias sociales, la democracia en la práctica abandona sus dogmas fundacionales y se abre a una concepción social. El día en que los regímenes partidocráticos, vayan de la mano de la investigación de mercado, descubrirán sus propios hallazgos, habrán descubierto la democracia orgánica. Gómez y Elena [5] se trata de despertar emociones útiles (convertibles en votos o en decisiones de compra). Por todo ello, no se puede dejar de lado un cierto sentido crítico, o incluso un escepticismo (p. 408).

El objeto de la investigación en el marketing político es identificar los conceptos de valor que permiten decir a los electores, así como los factores determinantes que influyen en la decisión del voto, es importante señalar que el estudio se realizó luego del paro nacional en Ecuador en contra de las medidas económicas decretadas por el Gobierno de Lénin Moreno. Es justamente por este motivo la investigación que identifica los conceptos de valor en los posibles precandidatos que se visibilizaron en el paro Nacional en octubre 2019.

Los pre-candidatos objeto del estudio pertenecen a partidos de derecha e izquierda, de la región costa y sierra.

Jaime José Nebot Saadi: Nació en Guayaquil, Guayas el 22 de octubre de 1946 es abogado y político ecuatoriano quién ejerció como alcalde de Guayaquil por 18 años, nueve meses y cuatro días: Desde el año 2000 hasta el 2019. El 14 de mayo de 2019 entregó la alcaldía a Cynthia Viteri tras casi 19 años como alcalde. Ha desempeñado cargos públicos como diputado por la provincia del Guayas en el antiguo Congreso Nacional del Ecuador y como Gobernador de la provincia del Guayas. Ha sido candidato a la Presidencia de la República del Ecuador en dos ocasiones, pertenece al partido de derecha, región costa.

Jaime Froilan Vargas Vargas: Nació el 21 de julio de 1979 es un líder indígena achuar, actualmente es presidente de la Confederación de Nacionalidades Indígenas 
del Ecuador (CONAIE), electo para el periodo 2017-2020. Fue parte del directorio administrativo financiero en la dirección Intercultural Bilingüe de la Nacionalidad Achuar del Ecuador en 2004. En 2013 asumió el cargo de presidente de la Nacionalidad Achuar de Ecuador (NAE), hasta el 2015. Asistió a la Corte Interamericana de Derechos Humanos de 2013, en Washington DC, durante la presentación de las demandas de violaciones territoriales y derechos colectivos. En 2015 obtuvo un Diplomado en Gestión Pública en Macas. En 2015 asumió la presidencia del Consejo de Participación Ciudadana y Control Social de Morona Santiago hasta el 2017. Pertenece al partido de izquierda, región sierra.

Guillermo Alberto Santiago Lasso Mendoza: Nación en Guayaquil el 16 de noviembre de 1955 es empresario, banquero y político ecuatoriano, conocido por ser presidente un ejecutivo y uno de los principales accionistas del banco de Guayaquil, también fundador y líder del Movimiento CREO por el que ha sido candidato a la presidencia de Ecuador en las Elecciones de 2103-2017. Ha desempeñado varios cargos en el sector público, durante el gobierno de Jamil Mahuad fue gobernador del Guayas y Superministro de economía, y en el gobierno de Lucio Gutiérrez fue asesor económico y embajador itinerante, pertenece al partido de derecha, región costa.

Yaku Pérez Guartambel: Nació en Cuenca, el 26 de febrero de 1969, nacido con el nombre de Carlos Ranulfo Pérez Guartambel, es un líder indígena ecuatoriano de la nacionalidad kichwa cañari. Fue presidente de la ECUARUNARI de 2013 a 2019, desde donde participó en manifestaciones contra el gobierno de Rafael Correa. En las elecciones seccionales de 2019 fue electo como Prefecto del Azuay. Pertenece al partido de izquierda, región sierra.

Abdalá Jaime Bucaram Ortiz: Nació en Guayaquil, el 4 de febrero de 1952 es un político y abogado ecuatoriano de origen libanés. Fundador del Partido Roldosista Ecuatoriano, fue presidente de Ecuador durante el período comprendido entre el 10 de agosto de 1996 y 6 de febrero de 1997, el cual finalizó con su destitución por parte del Congreso del Ecuador (44 votos a favor de 82 posibles) por incapacidad mental para gobernar Fue prófugo de la justicia ecuatoriana por 20 años hasta que los juicios en los cuales se le acusaba prescribieron, pertenece al partido de derecha, región costa.

Andrés Tarquino Páez Benalcázar: Nación el 28 de mayo de 1966 en Ibarra, Ecuador es un doctor en jurisprudencia, sociólogo, político, docente universitario y ex asambleísta nacional por la provincia de Pichincha por Izquierda Democrática, presidente Nacional de la Izquierda Democrática el 27 de enero de 2006 al 24 de mayo de 2009. Se postuló a la vicepresidencia en 2017. Pertenece al partido de izquierda, región sierra.

Los principales partidos y asociaciones políticas del país identificados son nueve: 
Movimiento PAIS: Es la agrupación política del Expresidente Rafael Correa y cuenta con una fuerte implantación entre los sectores sociales populares, pero también mantuvo una fuerte penetración en la clase media e incluso obtuvo votos entre los empresarios y personas de alto nivel económico y social. Desde su inicio, el Movimiento PAIS estaba más implantado en la sierra que en la costa, pero en las 9 últimas elecciones sus resultados han sido parejos en todo el país. Fue la primera fuerza política que tuvo la mayoría absoluta, con 100 asambleístas.

CREO: es un partido político fundado en $\mathbf{2 0 1 0}$ que defiende una visión liberal de la economía y las políticas públicas. Con Guillermo Lasso como líder, en 2013 pasó a ser la segunda fuerza política del país, con cerca del $25 \%$ de los votos en las elecciones presidenciales y un $12 \%$ en las legislativas.

Partido Social Cristiano (PSC): Fue durante muchos años la primera fuerza política ecuatoriana y representa la derecha conservadora del país. Tenía una sólida presencia en las provincias de la costa, principalmente en la provincia del Guayas.

Partido Sociedad Patriótica del 21 de enero (PSP): Partido creado por el expresidente de la República Lucio Gutiérrez, participo en las elecciones de 2009 y se convirtió en ese momento en la segunda fuerza electoral del país.

Pachakutik: Es el partido político de los grupos indígenas y tiene gran presencia en la zona de la sierra. Sus movilizaciones en anteriores gobiernos en contra de la negociación del TLC con Estados Unidos y de las políticas petroleras, generaron tensiones políticas, huelgas y paros generales en algunas provincias de la serranía. Tras haber sido aliados del gobierno al inicio de su mandato, hoy forman parte de la oposición y se presentaron a las elecciones dentro de AUPI (Alianza Unida Plurinacional de las Izquierdas).

Partido Roldosista Ecuatoriano (PRE): Fue fundado en 1982 por Abdalá Bucaram Ortiz. Tiene un estilo personalista y populista.

Movimiento SUMA, Sociedad Unida Más Acción: Es un partido creado en 2012 que se define de centro.

Partido Revolucionario Independiente Acción Nacional (PRIAN): Partido de ideología conservadora y de corte populista, creado por Álvaro Noboa, una de las principales fortunas del país y primer exportador de banano, que en tres ocasiones consecutivas ha llegado a participar en la segunda vuelta en la elección presidencial.

AVANZA: Este partido fue creado en 2012 por ex militantes de la Izquierda Democrática -Ramiro González y John Argudo-. En las últimas elecciones no presentaron candidaturas a presidente y vicepresidente de la República porque decidió apoyar a Rafael Correa y Jorge Glass. 


\subsection{Partidos de izquierda y derecha}

La política nos define como ciudadanos. Aunque pensemos que el sistema no funciona, o que ningún partido político no nos representa, nuestra ideología se define a partir de los valores y la forma de pensar del electorado. Al hablar de política de izquierda o derecha y en que se diferencian, hay que tener claro que estas políticas son diferentes en cada país, dependiendo de la forma en que esté organizado el gobierno, sus leyes y sus instituciones.

Por ejemplo, las políticas de izquierda en un estado socialista como Suecia, donde el gobierno corre con los gastos de los servicios públicos, son muy diferente a la izquierda en los Estados Unidos, un país capitalista donde la economía condiciona todos los aspectos de la vida (educación, salud, prestaciones laborales).

Se trata de una diferencia de enfoque a la hora de gobernar. Según la ideología de izquierda, para que un país funcione hay que fortalecer el conjunto de la sociedad y los servicios básicos (sanidad, sistema educativo, pensiones); mientras que la derecha sitúa al individuo en el centro de su política. A grandes rasgos, la ideología de izquierda desarrolla sus políticas pensando en la sociedad, definida como un conjunto de personas que forman una comunidad. Por eso algunos gobiernos o partidos de izquierdas se definen como socialistas.

Las medidas de izquierdas tienen como objetivo crear un estado del bienestar del que puedan beneficiarse todas las personas. Este sistema está sufragado por los impuestos que pagan los ciudadanos, cada uno en función de sus posibilidades (en principio, quienes perciben más ingresos pagan más impuestos que los que ganan menos).

Por otro lado, la ideología de derecha está centrada en el individuo y la iniciativa privada. Los gobiernos de derechas favorecen la economía de las empresas para que sean éstas las que generen la riqueza en un país. Este tipo de políticas se definen como liberales, porque las autoridades intervienen el capitalismo, porque el funcionamiento del Estado gira en torno al dinero o capital. Por eso, los gobiernos de derecha suelen beneficiar más a los empresarios (porque son los que generan dinero) que a los trabajadores.

\subsection{Origen histórico de la izquierda y derecha}

La asociación de la derecha con las clases más ricas y la izquierda con la base popular tiene su origen en la Asamblea Nacional del parlamento de Francia. El año 1789 marcó el inicio de la Revolución Francesa, una revuelta que cuestionaba el poder de la monarquía que quería acabar con los privilegios de la aristocracia. Los meses de agosto y septiembre de ese año, los miembros de la Asamblea tuvieron que votar sobre el 
veto real, es decir, si el rey de Francia debía tener la capacidad de rebatir cualquier ley, aunque hubiera sido aprobada por mayoría en el parlamento. Durante la votación, los nobles y el clero (las clases más ricas y partidarias de la monarquía) se situaron a la derecha del presidente de la Asamblea, mientas que los revolucionarios contrarios al veto real se situaron a la izquierda.

Esta dualidad política se extendió por el continente y hoy en día todavía existe en muchos países de Europa: republicanos y socialistas en Francia, conservadores y laboristas en el Reino Unido, liberales y socialistas en Bélgica o populares (PP) y socialistas (PSOE) en España.

\subsection{Parámetros de medición de los conceptos de valor en los precadidatos}

Credibilidad: La credibilidad del candidato es esencial en la integración de un partido político, que tiene una relación directa de los antecedentes políticos, de honradez, liderazgo, tolerancia y otros aspectos importantes que evalúa el elector en el candidato.

Leines [6] manifiesta que: Existen muchas formas de crear credibilidad, más aún en la actualidad con los medios electrónicos, las redes sociales que cada vez están más activos en política para hacer propaganda política sin ser censurada como en otros medios como la televisión, la radio, los periódicos, etc. El futuro de los partidos políticos dependerá de relación y vinculación de la ciudadanía y la credibilidad a las propuestas para satisfacer las necesidades de los votantes.

Antedentes politicos: En importante destacar la participación de los políticos que se postulan como futuros candidatos presidenciales, la ciudadanía evalúa su trayectoria en la política, con el fin de identificar sí existió o no honestidad o actos de corrupción.

Honradez: La política es el vehículo por el bien común de una sociedad que busca el bienestar social, la prevalencia del orden y la ley para proteger a todos por igual. A los políticos se les exige que sean correctos en sus actuaciones, sobre todo, en lo referente a las cuentas públicas. Los conductores de la sociedad deben ser honestos al gestionar los recursos públicos, en la actualidad está el robo, la corrupción, el enriquecimiento ilícito de políticos que llegan al poder, que muchos son presionados por propios y extraños a cometer estos actos de corrupción, como consecuencia existe la falta de coherencia política, se dan casos de políticos que han comprado una casa de miles y millones de dólares cuando antes de ingresar al poder no tenían esa posibilidad. La incoherencia y las irregularidades, genera el problema que estriba en que no cuadra con lo predicado, o al menos, con el concepto de político de izquierdas que todos tenemos en mente. Políticos que de la nada, han atesorado grandes fortunas. no es equiparable la compra de bienes con dineros del estado, la corrupción es protagonizada por numerosos cargos públicos. En asuntos de dinero, la honradez es importante. 
Formacion profesional: Si cualquier actividad requiere de profesionales de calidad no es menor la exigencia en la política. Ahora bien, los estudios sobre la calidad de la política han avanzado en los últimos años totalmente divorciados en las existencias de políticos de calidad. Pareciera que no hubiera relación alguna entre políticos y política; sin embargo, el éxito se vinculaba con el material humano que debería ser de alta calidad.

La literatura producida en la última década en torno a la calidad de la democracia [7]; Diamond y Morlino [8] y Levine y Molina [9] apenas ha puesto su atención en el papel que desempeñan los políticos, sus conocimientos, la capacidad de respuesta y su actuación como ejecutores políticos responsables de las políticas públicas [10].

Recientes estudios están girando hacia la necesaria relación entre la calidad de la democracia y la calidad de los políticos. Se reivindica el papel de los políticos profesionales en los procesos de democratización, se denuncia la responsabilidad de los malos políticos en los problemas de la democracia representativa y se vincula a la calidad de la democracia deliberativa con la calidad de sus representantes [11].

Alcántara [12] manifiesta que los nuevos políticos necesariamente requieren de nuevas habilidades y de un entrenamiento técnico especializado para ejercer su cargo.

Liderazgo: El liderazgo político se asocia a la capacidad de mandar sobre otros y lograr que estos cumplan la voluntad del líder. El verdadero liderazgo es la capacidad de influir en los actos de los demás, hacerlos parte de la decisión, la ejecución y los resultados.

Romero [13] da un ejemplo de liderazgo político que supo ejercer el poder e influir en la vida de millones de personas es Nelson Mandela, quien luego de años en prisión luchó por una causa, logró conquistar el poder y supo trabajar las inquietudes que inspiraron sus luchas quien no llegó al poder para improvisar, se retiró del poder cuando su pueblo le seguía queriendo y el poder moral lo acompaño hasta el último de sus días.

La figura de la autoridad es precisamente el poder que recae sobre una posición que se ejerce en la investidura misma del cargo, pero la influencia es la capacidad de cambiar el pensamiento de los demás, las opiniones o el desenlace de una acción.

El verdadero liderazgo político es el que sabe navegar en tiempos de crisis, el que tiene resiliencia como capacidad para adaptarse a las adversidades; pero, sobre todo, el que sabe tomar decisiones en tiempos difíciles.

Carisma: Según [14] el carisma político, estudiado por M. Weber, se manifiesta con inmediatez y espontaneidad, sin necesidad de explicación ni de coacción, expresando las necesidades y aspiraciones latentes de los hombres y asumiendo con lógica evidencia la tarea de conducir un momento de la historia de un pueblo hacia un destino preanunciado. 
Maquiavelo y Feud [15] hace referencia a una virtud natural que surge espontáneamente en algunas personas. Una virtud que permite agradar, atraer, seducir y encantar a las demás personas. Al final del día esa virtud del carisma reside en la personalidad. Una personalidad que facilita el liderazgo político en la medida que se manifiesta espontáneamente y despierta simpatías y reacciones emocionales favorables.

Como los votantes votan por las personas y no solo las ideas, entonces la personalidad del candidato pasa a ser un factor altamente relevante de la decisión de voto. Para muchos candidatos eso es bueno: Su personalidad carismática y rápidamente se convierte en populares y ganan adhesiones entre el electorado. Pero que otros políticos no lo logran. Su personalidad no cautiva, no conecta, no mueve las emociones y no facilita el liderazgo. Entonces, decimos que no es carismático. Esa falta de carisma se convierte rápidamente en un problema para una campaña electoral, lo mismo que para la aprobación de un gobierno o la simpatía hacia un partido político.

Es así como el candidato es sujeto de una 'intervención' se cambia el modo de vestir, se desarrolla su discurso, con pautas estrictas sobre cómo tiene que actuar y hablar, se prescriben nuevos comportamientos y actitudes, e impulsan a mostrarse diferente a como es realmente y se realiza una nueva identidad pública. Pero, la percepción del elector al identifica cuando el candidato no es auténtico, puede destruir a aflorar su imagen, también es importante saber que el liderazgo político es creado por el marketing y el carisma de políticos también. En este sentido, descubrir en la propia personalidad del candidato el rasgo psicológico real que será la base de su conexión con los posibles votantes.

Tolerancia: Hablar sobre tolerancia es incursionar en uno de los temas cruciales para entender la política y la cultura del Occidente. El desarrollo de la sociedad y la cultura democrática, así como de la política del reconocimiento y del multiculturalismo, conduce a la vigencia de la tolerancia. Walzar [16] tiene un tratado en el que ubica el desarrollo de la tolerancia en diversas formas de vida, cultura y política de las comunidades que son necesarias y de sobrevivencia.

Según Sassier [17], la tolerancia adquirió un sentido positivo hacia finales del siglo $\mathrm{XVI}$ y, en concreto, en los textos que defienden el edicto de Nantes. La intolerancia había tenido un impulso decisivo con el monoteísmo religioso. Al resquebrajarse la unidad religiosa en el Occidente medieval, sobrevinieron la violencia y la guerra. Las facciones religiosas ven en el otro la personificación de la maldad. La persecución y ejecución de los herejes muestra la intolerancia. La lucha del bien contra el mal no permite concesiones ni contemplaciones, así que luego de matarse y aniquilarse entre sí, se accede a una conciencia de época en la que se asume la actitud de tolerar al que no es como nosotros. La tolerancia moderna empieza por ser religiosa y se extiende luego a otros planos. 
Tejada [18] la tolerancia aparece en los escritos de autores liberales como Spinoza y Locke, pero adquiere carta de naturalización plena con la Revolución inglesa. Las diferencias locales y regionales, étnicas y raciales, religiosas e ideológicas, pueden quedar superadas en la gestación de un espacio público común.

La intolerancia a quien piensa diferente se persigue y se condenan las formas que se resisten al poder nacional. La formación de un espacio público nacional homogéneo en el que se pueda dar la tolerancia entre los ciudadanos pares e iguales tuvo que darse con mecanismos intolerantes ante quienes no se consideraba ciudadanos con pleno derecho.

La tolerancia consiste en 'aceptar' lo que es diferente a lo que pensamos o sentimos. Cuando no existe la tolerancia, sobrevienen la guerra y el conflicto permanente. Aquello que es diferente, extraño o exótico puede alterar y molestar. La respuesta instintiva y primitiva nos lleva a la violencia contra los otros.

En la política la intolerancia es de exterminio y de aniquilación del adversario. Quien asume un punto de vista más relativo y contextual puede llegar a valorar como positiva la diversidad. Aquí no se soporta al otro, sino que se le ve como alguien diferente de quien se puede aprender y rescatar algo.

La tolerancia tiene la intención abierta de entender y comprender lo diferente. Walzer ubica cinco niveles de la tolerancia: La tolerancia religiosa, consiste en la aceptación resignada de la diferencia para mantener la paz. Una segunda postura refleja un estado de indiferencia, pasiva y relajada ante la diferencia. La tercera es reconocer el derecho que tienen los otros a ejercer sus atributos, aunque no sean atractivos para nosotros. La cuarta forma expresa apertura, curiosidad, ganas de aprender, en tanto que la quinta actitud tolerante es de adhesión y admisión entusiasta por la diferencia. Como puede observarse, la tolerancia se ha desarrollado desde su manifestación más elemental hasta una adhesión entusiasta por abrirse a otros mundos y realidades.

La primera de las formas de la tolerancia es importante porque refleja el paso de una política violenta y conflictiva a un tipo de política pacífica que difiere y neutraliza el conflicto. En algunas interpretaciones sobre el ejercicio de la política, ésta se nos presenta como fuente de conflicto, o bien, como elemento de orden y estabilidad.

La política como conflicto tiene en Maquiavelo a uno de sus más importantes exponentes. En esta línea, la política es un campo de fuerzas conflictivas. El poder puede recubrir y esconder la violencia.

La tolerancia primaria acepta a las diferencias, una política de rechazo genera conflictos. Los que piensan diferente se ven obligados a convivir y coexistir. En ocasiones estas situaciones de tolerancia son generadas después de largos choques y combates bélicos y políticos. Las guerras religiosas llevaron a una actitud de mayor prudencia ante los adversarios, los enemigos o simplemente ante quien no es como uno. 
La política de la tolerancia, en tanto, tiende a evitar la guerra y difiere los pleitos y las ofensas. Sólo en condiciones sumamente excepcionales se vuelve a quebrantar el orden y la estabilidad de las partes. En lo fundamental, las partes en conflicto aprenden a tratar al otro y buscan la reciprocidad de su contraparte.

La tolerancia es observar desde una posición distinta, ajena desde todo punto de vista misma que gana adeptos del campo contrario. Un líder es un traficante de esperanzas, no sería un buen líder si no tiene la capacidad de ser tolerante.

\section{Materiales y Métodos}

La presente investigación aplica los conceptos de valor social en la percepción de los votantes en los posibles precandidatos presidenciales en las Elecciones presidenciales del año 2021 en Ecuador, la investigación de enfoque cualitativo y cuantitativo, de nivel descriptivo, observacional y prospectivo, de diseño transversal no experimental, se aplicó los métodos lógicos: inductivo, deductivo, analítico, sintético y sistémico en la revisión documental y en el proceso de la investigación. El objetivo de la investigación fue determinar los parámetros de medición del concepto valor social para evaluar la aceptación/rechazo de los electores en seis posibles precandidatos, la investigación muestra limitación en la provincia de Chimborazo, región sierra, luego de los hechos sucedidos el pasado octubre-2019. A continuación, se detalla el proceso realizado en la investigación:

1. La Técnica aplicada fue la encuesta, a través de un cuestionario de preguntas.

2. El Universo: Chimboracenses, hombres y mujeres mayores a 18 años, pertenecientes al cantón Riobamba, Región Sierra.

3. El Muestreo: 380 posibles votantes, el muestreo fue Probabilístico, No estratificado.

4. La fecha de aplicación fue: 18 de octubre de 2019, luego de las protestas del 2 de octubre de 2019 (11 días de paralización)

5. Las imágenes de los precandidatos fueron recolectadas en sitios de internet públicos. No se realizó ninguna manipulación en las fotografías.

6. Los conceptos de valor fueron analizados por expertos políticos y economistas que consideraron 7 parámetros de análisis en los precandidatos: Credibilidad; Antedentes politicos; Honradez; Formacion profesional; Liderazgo; Carisma y Tolerancia.

7. Los 7 parámetros de medición determinan los conceptos del valor social que se aplicó en la encuesta. 
8. Encuesta estructurada sobre asociación de conceptos-precandidatos en pares.

9. Registro de tiempo de respuesta por reactivo.

10. Respuesta se registra en escala de Likert de 1 al 5 que muestra la coherencia entre imagen-concepto valor social.

11. Seis imágenes de precandidatos presidenciales analizados en pares.

12. El análisis se realizó luego de los sucesos ocurridos en Ecuador del 2 al 13 de octubre de 2019. Luego del Paro Nacional donde las precepciones de los precandidatos cambiaron notablemente.

\section{Resultados y Discusión}

A continuación, se presentan los resultados, para la Encuesta se aplicó la Escala de Likert con los siguientes parámetros de medición:

1: Muy bajo; 2: Bajo; 3: Medio; 4: Alto y 5: Muy alto.

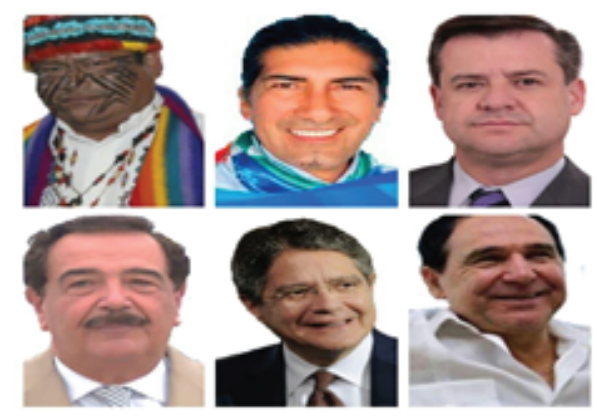

Figure 1

Seis precandidatos presidenciales elecciones Ecuador 2021.

La Tabla 1 presenta el resumen de los resultados obtenidos en la encuesta aplicada a 380 posibles electores de las elecciones a la presidencia en Ecuador en el 2021.

Análisis comparativo 1: Los precandidatos Jaime Nebot y Jaime Vargas los conceptos de valor credibilidad: 65\% Nebot-87\% Vargas; Antecedentes políticos: 50\% Nebot-40\% Vargas; Honradez: 63\% Nebot-75\% Vargas; Formación profesional: 80\% Nebot-85\% Vargas; liderazgo 62\% Nebot- 85\% Vargas; carisma: 57\% Nebot-65\% Vargas, Tolerancia 57\% Nebot-65\% Vargas. En el análisis de este binomio se puede observar una mayor aceptación para el precandidato Jaime Vargas quien participó en el movimiento indígena en el pasado octubre 2019. El precandidato Jaime Nebot fue acusado de racismo y xenofobia por los manifestantes indígenas por dar su apoyo a la alcaldesa de Guayaquil Cintia Viteri, los militantes declararon personas no gratas y racistas a Jaime Nebot, Cintia Viteri y los Bucaram. 


\section{Table 1}

Resumen de seis precandidatos presidenciales elecciones 2021.

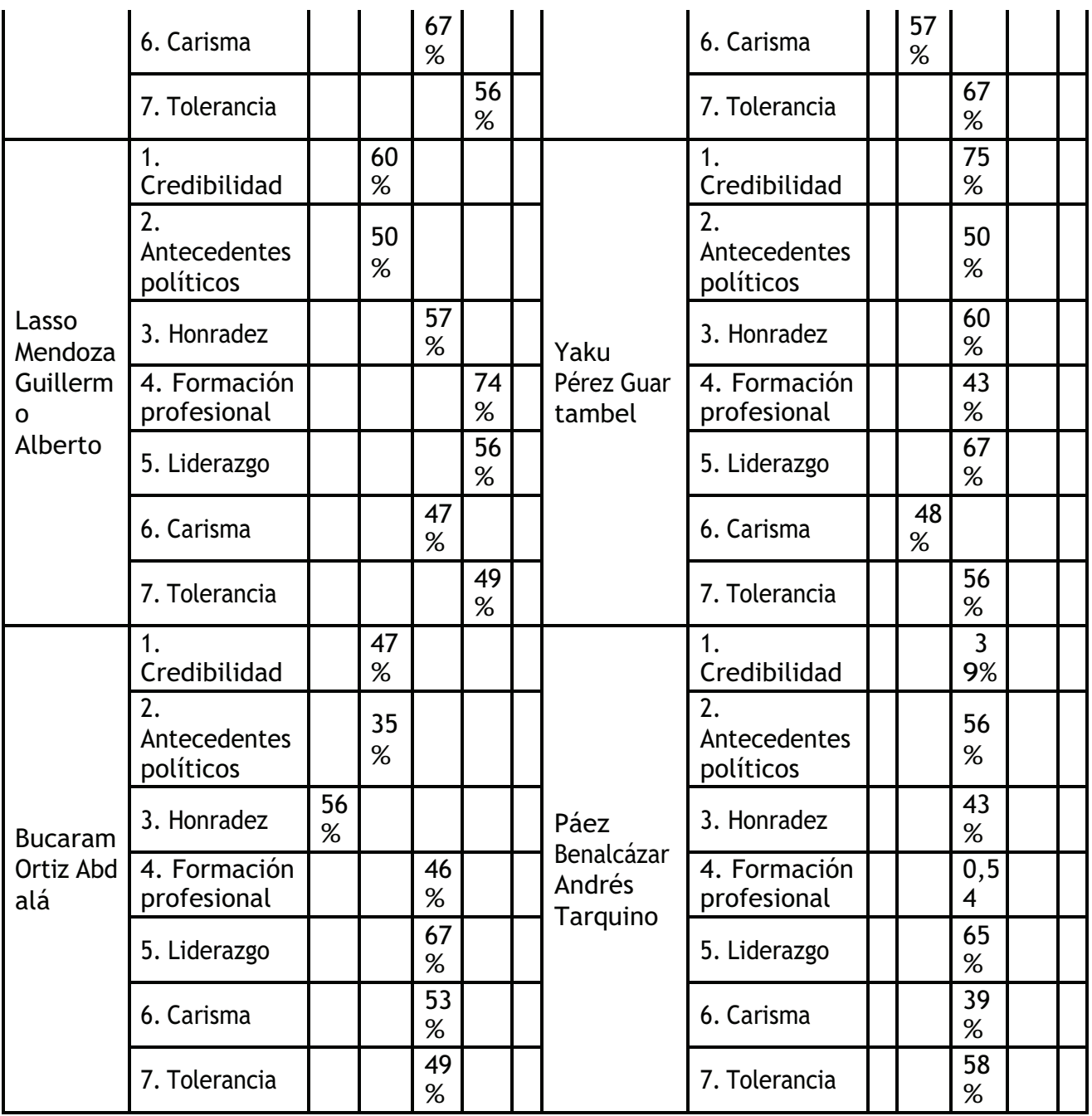

Table 2

Precandidatos Jaime Nebot y Jaime Vargas.

\begin{tabular}{|l|l|l|l|}
\hline \multirow{3}{*}{} & CONCEPTOS DE VALOR & NEBOT & VARGAS \\
\cline { 2 - 4 } & Credibilidad & $65 \%$ & $87 \%$ \\
\hline & Antecedentes políticos & $50 \%$ & $40 \%$ \\
\cline { 2 - 4 } & Honradez & $63 \%$ & $75 \%$ \\
\cline { 2 - 4 } & Formación profesional & $80 \%$ & $85 \%$ \\
\cline { 2 - 4 } & Liderazgo & $62 \%$ & $85 \%$ \\
\cline { 2 - 4 } & Carisma & $57 \%$ & $65 \%$ \\
\cline { 2 - 4 } & Tolerancia & $67 \%$ & $56 \%$ \\
\hline
\end{tabular}

Investigación de campo.

Análisis comparativo 2: Guillermo Lazo y Yaku Pérez los conceptos de valor analizados credibilidad: 60\% Lazo-75\% Yaku; Antecedentes políticos: 50\% Lazo-50\% Yaku; 


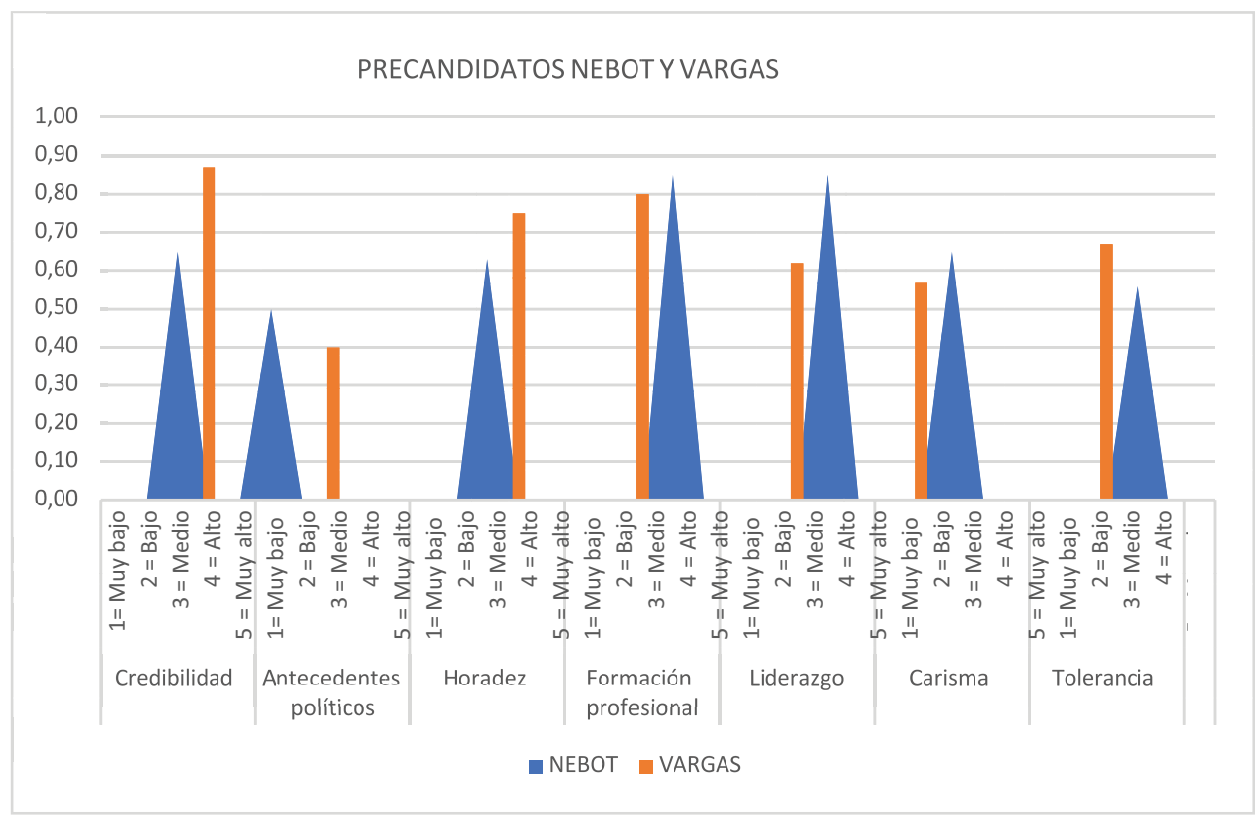

Figure 2

Jaime Nebot y Jaime Vargas. Fuente: Investigación de campo.

Table 3

Guillermo Lazo y Yaku Pérez.

\begin{tabular}{|l|l|l|l|}
\hline & CONCEPTOS DE VALOR & LAZO & YAKU \\
\cline { 2 - 4 } & Credibilidad & $60 \%$ & $75 \%$ \\
\hline Antecedentes políticos & $50 \%$ & $50 \%$ \\
\cline { 2 - 4 } & Honradez & $57 \%$ & $60 \%$ \\
\hline Formación profesional & $43 \%$ & $74 \%$ \\
\hline & Liderazgo & $67 \%$ & $56 \%$ \\
\hline & Carisma & $48 \%$ & $47 \%$ \\
\cline { 2 - 4 } & Tolerancia & $56 \%$ & $49 \%$ \\
Fuente:
\end{tabular}

Investigación de campo.

Honradez: 57\% Lazo-60\% Yaku; Formación profesional: 43\% Lazo-74\% Yaku; liderazgo 67\% Lazo-56\% Yaku; carisma: 48\% Lazo-47\% Yaku, Tolerancia 48\% Lazo-47\% Yaku. En el análisis de este binomio se puede observar una mayor aceptación para el precandidato Yaku Pérez. En el análisis de este binomio se puede observar una mayor aceptación para el precandidato Yaku Pérez quien participó en el movimiento indígena en el pasado octubre 2019.

Análisis comparativo 3: Abdalá Bucaram y Andrés Paéz los conceptos de valor analizados credibilidad: 47\% Bucaram-37\% Paez; Antecedentes políticos: 56\% Bucaram43\% Paez; Honradez: 46\% Bucaram-54\% Paez; Formación profesional: 67\% Bucaram65\% Paez; liderazgo 39\% Bucaram-53\% Paez; carisma: 65\% Bucaram-87\% Paez, Tolerancia 65\% Bucaram-87\% Paez. En el análisis de este binomio se puede observar 


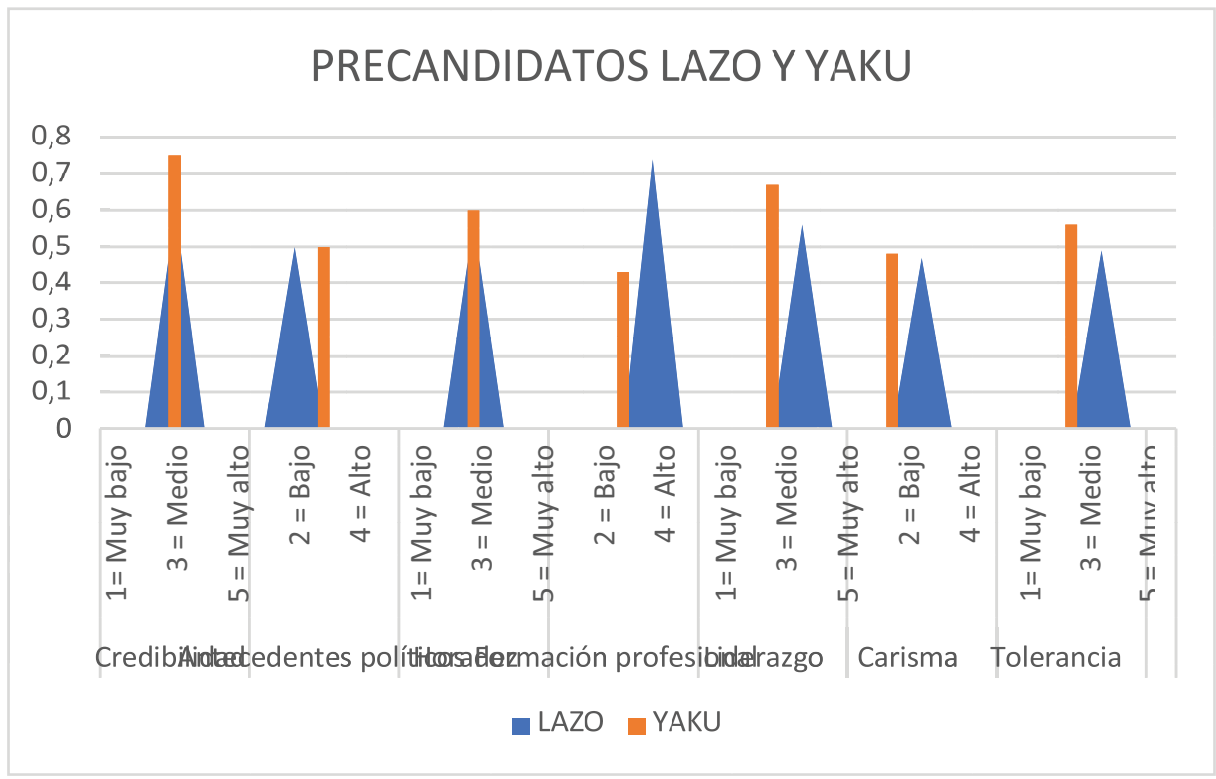

Figure 3

Guillermo Lazo y Yaku Pérez. Fuente: Investigación de campo.

Table 4

Precandidatos Abdalá Bucaram y Andrés Paéz.

\begin{tabular}{|l|l|l|l|}
\hline & CONCEPTOS DE VALOR & BUCARAM & PAÉZ \\
\cline { 2 - 4 } & Credibilidad & $47 \%$ & $39 \%$ \\
\cline { 2 - 4 } & Antecedentes políticos & $35 \%$ & $56 \%$ \\
\hline Honradez & $56 \%$ & $43 \%$ \\
\cline { 2 - 4 } & Formación profesional & $46 \%$ & $54 \%$ \\
\hline & Liderazgo & $67 \%$ & $65 \%$ \\
\cline { 2 - 4 } & Carisma & $39 \%$ & $56 \%$ \\
\cline { 2 - 4 } & Tolerancia & $49 \%$ & $58 \%$ \\
\hline
\end{tabular}

Investigación de campo.

una mayor aceptación para el pre-candidato Andrés Páez quien no participó en el movimiento indígena en el pasado octubre 2019 se mantuvo al margen, pero sin haber participado Abdala Bucarám por ser de la costa, existe una valoración menor en los conceptos de valor por parte de los electores de la sierra ecuatoriana por el aspecto antes mencionado.

\section{Conclusiones}

La valoración de los conceptos de valor social determinados por expertos políticos fueron los siguientes: Credibilidad, Antedentes políticos, Honradez, Formacion profesional, Liderazgo, Carisma y Tolerancia, estos conceptos se aplicaron en encuestas 


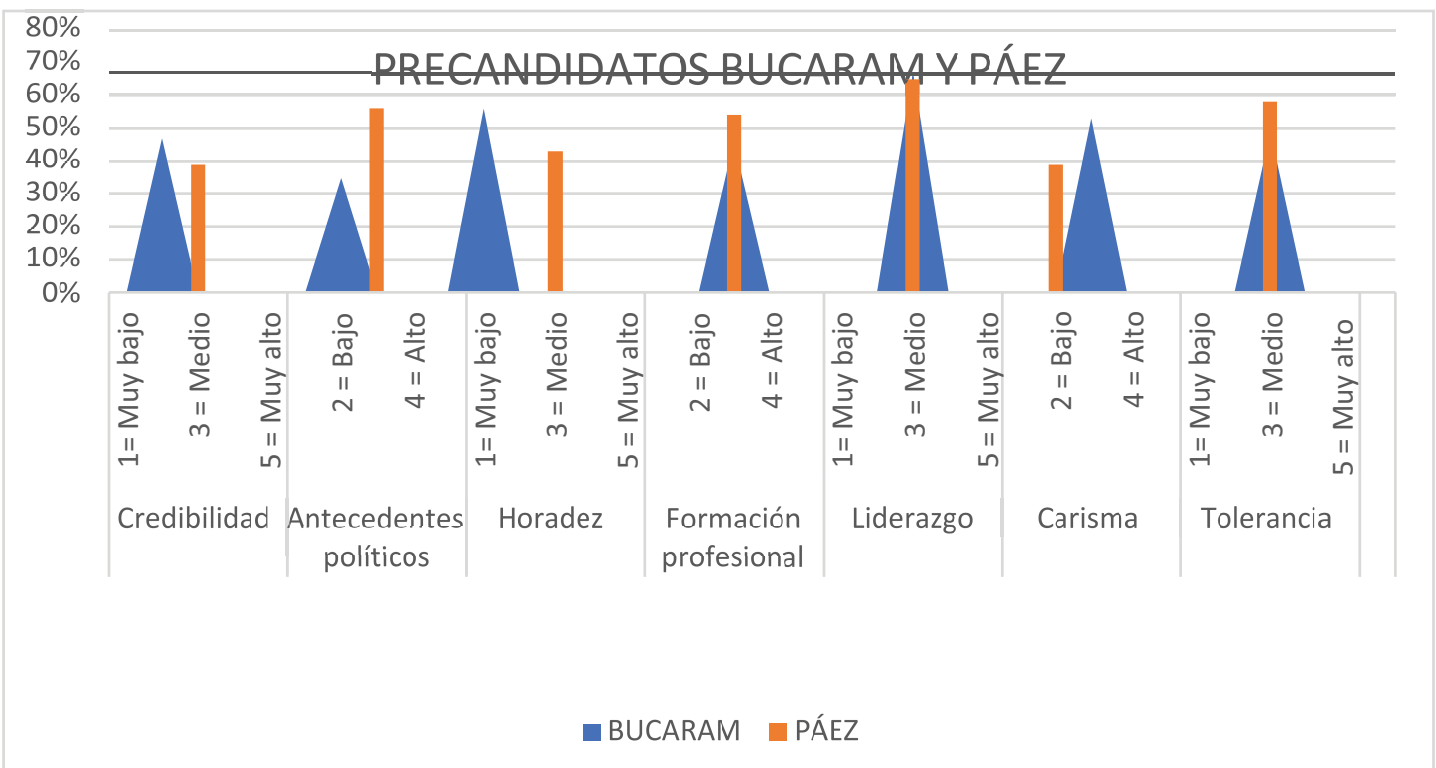

Figure 4

Bucaram y Paéz. Fuente: Investigación de campo.

en los electores o votantes para determinar la aceptación o rechazo de los posibles precandidatos presidenciales para las elecciones de 2021 en Ecuador.

Al realizar un estudio de mercado con los conceptos de valor social que debe poseer el precandidato, se determinó la aceptación hacia los dirigentes de los movimientos políticos que participaron en octubre 2019 tras la paralización nacional en el Ecuador en contra de las medidas económicas del decreto 883. El rechazo a estas medidas fue realizado por un conjunto de gremios, comunidades indígenas y otros frentes existiendo una conglomeración de las masas que defendían sus derechos y exigían ser escuchados. El estudio determinó limitantes; puesto que, al realizarse en la sierra ecuatoriana y en la provincia de Chimborazo donde existe mayor población indígena, limita el comportamiento de los resultados que pueden variar, si se aplica en otra provincia y región. En este caso los resultados fueron marcados hacia la aceptación a los candidatos de la región sierra; por lo tanto, este estudio servirá de referente para futuras aplicaciones en otras ciudades y regiones con el fin de realizar comparativos posteriores, y observar si se ratifican los resultados en cuanto a la aceptabilidad de los posibles precandidatos presidenciales para las elecciones de 2021 en Ecuador.

El análisis interpretativo de los resultados obtenidos en la investigación de los seis precandidatos en las Elecciones 2021 se realizó a través de un estudio comparativo en parejas de los precandidatos de derecha e izquierda (costa vs sierra-oriente) los resultados fueron:

Los precandidatos Jaime Nebot y Jaime Vargas analizados los conceptos de valor; existe mayor credibilidad para Vargas; en cuanto a los antecedentes políticos, tiene 
mayor antecedentes Nebot; Honradez mayor percepción para Vargas; en tanto que en la Formación profesional casi es el mismo valor para Nebot y Vargas; la percepción de liderazgo, carisma y tolerancia es percibido en mayor forma para Vargas. En conclusión, en esta comparativa de este binomio se puede observar una mayor aceptación para el precandidato Jaime Vargas.

La segunda comparativa fue de Guillermo Lazo y Yaku Pérez los conceptos de valor analizados fueron: Credibilidad mayor para Yaku; Antecedentes políticos la percepción es mayor en los dos precandidatos Lazo y Yaku; Honradez mayor percepción en Yaku con una diferencia mínima en Lazo, la Formación profesional es mayor para Yaku; el liderazgo es mayor en Lazo, el carisma se encuentra casi a la par con una diferencia mínima para los dos candidatos, de igual manera en la Tolerancia. En el análisis comparativo de este binomio se puede observar una mayor aceptación para el precandidato Yaku Pérez, pero con diferencias muy mínimas en los conceptos analizados.

La tercera comparación entre Abdalá Bucaram y Andrés Páez los conceptos de valor analizados en cuanto a la credibilidad y antecedentes políticos es mayor en Bucaram, en tanto que la Honradez en mayor en Páez; la Formación profesional en mayor en Bucaram; el liderazgo es mayor en Páez; el carisma y tolerancia es mayor para Páez. En el análisis comparativo de este binomio se puede observar una mayor aceptación para el precandidato Andrés Páez.

Los 7 parámetros evaluados entre candidatos de partidos de derecha y Región Costa y partidos de izquierda - Región Sierra, al ser aplicado el estudio en la región sierra especialmente de la provincia de Chimborazo que denota la marcada aceptación de los precandidatos postulantes de la Región Sierra. Se sugiere en aplicar este estudio en todas las provincias para determinar si prevalecen los mismos resultados.

Para finalizar una reflexión, hoy no es posible concebir la política sin una exhaustiva investigación que analice los determinantes o conceptos de valor social que percibe el colectivo de lectores en los pre-candidatos presidenciales, los 7 conceptos encierran la percepción que debe formar parte en el futuro candidato, la Credibilidad, Antedentes políticos, Honradez, Formación profesional, Liderazgo, Carisma y Tolerancia.

\section{References}

[1] Collins N, Butler P. Marketing político. Estructura y Proceso. European Journal of Marketing. 1994;28(1):19-34.

[2] Ramos R, Audivert N, Alilés A, Ramos M, Quintana M. Del marketing político a la neuropolítica: Las neurociencias para medir el comportamiento del producto y consumidor político. 2017;10. 
[3] Morales A. Significado de Valores sociales. Significados.com. 2019 November 11. Available from: https://www.significados.com/ valores-sociales/\#:\$\{lsim\}\$:text=Es\{\%]20importante\{\%\}20resaltar\{\%\}20que\{\%\}2Olos, los\{\%\}20valores\{\%\}20sociales\{\%\}20m\{\%\}C3\{\%\}A1s\{\%\}20importantes.. [Último acceso: 14 junio 2020].

[4] Alonso JU. Marketing Político. Gestión; 2000.

[5] Gómez M, Elena B. El neuromarketing: Una nueva disciplina para la investigación de audiencias y de la opinión pública. ICONO14, Revista de comunicación y tecnologías emergentes. 2014;12(2):395- 415.

[6] Leines EO. Credibilidad en los partidos políticos. Universidad Autónoma del Estado de Hidalgo.

[7] O'Donnell G, Vargas J, lazzetta O. The Quality of democracy: Theory and applications. Notre Dame: University of Notre Dame; 2004.

[8] Diamond L, Morlino L. Assesing the quality of democracy. The Johns Hopkins University Press; 2005.

[9] Levine D, Molina J. The quality of democracy in latin America. Boulder: Lynne rienner. Boulder: Lynne Rienner; 2011.

[10] Powell G. The chain of responsiveness. Assesing the quality of democracy. Baltimore: The Johns Hopkins University Press; 2005.

[11] Bermeo N. Ordinary people in extraordinary times. The citizenry and the breakdown of democracy. Princeton: Princeton University Press; 2003.

[12] Alcántara M. Calidad de los políticos, profesionalización y formación. Dialnet, 2011.

[13] Romero G. Liderazgo político: La capacidad de influir y decidir en tiempos difíciles. Telesur.

[14] Enciclopedía. Edumed.Net. 2019 October 31. Available from: http://www.eumed.net/ diccionario/definicion.php?dic=3\&def=187.

[15] Maquiavelo, Feud. Psicología para cambiar la política. Maquiaveloyfreud.com. 2019 October 31. Available: https://maquiaveloyfreud.com/ carisma-politico-metodo-miguel-angel/.

[16] Walzar M. Tratado sobre la tolerancia. Barcelona: Paidós; 1998.

[17] Sassier P. Tolerancia, ¿para qué?, México: Taurus; 2002.

[18] Tejada JL. La política de la tolerancia. Vol. 21. México: Politica y cultura; 2004.

[19] Lavareda A. Nueropolítica: El papel de las emociones. USP. 2011:120-146.

[20] Instituto Valenciano De Neurología Pediátrica (INVANEP). INVANEP. 2018 June 13. Available from: https://invanep.com/blog_invanep/ historia-y-avances-de-la-electroencefalografia-eeg. 